\title{
A Review on Pay-Per-Click Business Model
}

\author{
Kranti Kolambe Anish Nalawade Arnav Dhiwar Aditya Shahade Sanket Deokate \\ Lecturer, Dept. of IF, Student, Dept. of IF, Student, Dept. of IF, Student, Dept. of IF, Student, Dept. of IF, \\ MIT Polytechnic, MIT Polytechnic, \\ Pune \\ Pune \\ MIT Polytechnic, \\ Pune \\ MIT Polytechnic, \\ Pune

\section{MIT Polytechnic,}

\begin{abstract}
PPC is an advertising model. The advertiser has to pay every single time when his/her ad is clicked. Pay-Per-Click is also called as Cost-Per-Click (CPC) model. Pay-Per-Click marketing is a method of practicing search engine advertising to create clicks to the website, rather than "gaining" those clicks essentially. Pay-Per-Click is form of digital marketing. Pay-Per-Click is acknowledged for the various advantages it offers, and at an equivalent time, it's notably criticised for fraud and other issues related to its use.
\end{abstract}

\section{Keywords}

Pay-Per-Click, Cost-Per-Click, organically, criticised.

\section{INTRODUCTION}

Effective measures and quality research has been done throughout the years regarding digital advertising and digital marketing which has proven itself by getting critically acclaimed. The implementation of digital advertising and its effective execution in today's virtual market shed light upon the keen factors that help in developing a digital market world where all the needs of a consumer can be met. The help of computerised technology and its proper resource utilisation, has led the market to step up to go digital, it is of critical importance that the market remains digital due to the heavy traffic of consumers being online. There are various types of digital marketing channels which are discussed in the succeeding paragraph.

1. Secure the Doors

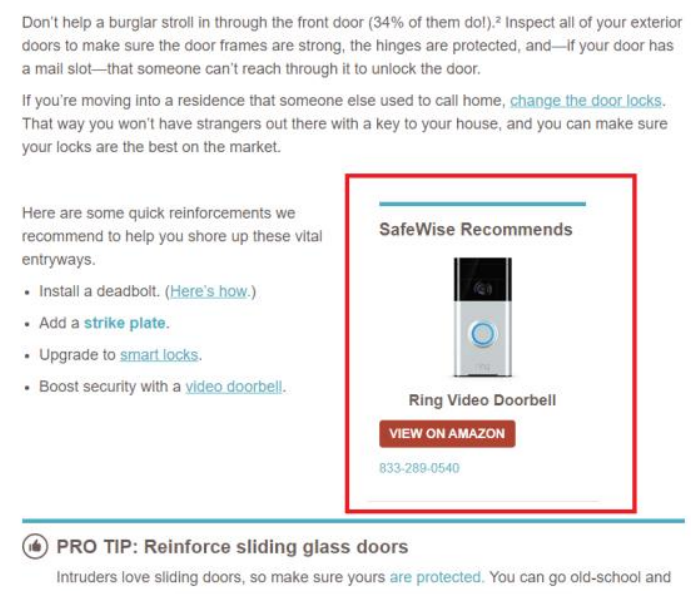

Fig. 1: Affiliate Marketing [1]

Affiliate marketing is a type of digital marketing where an affiliate places advertisements for advertising/marketing another person's or company's products and earns a commission. The affiliate simply searches for a product they enjoy, then promotes that product, and earns a touch of the cash in of every sale they create.[2]

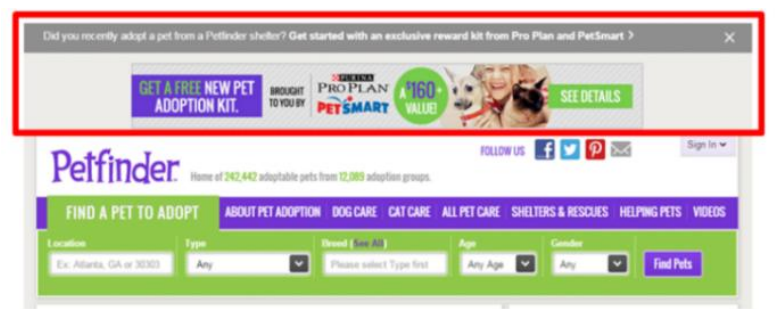

Fig. 2: Display Advertising [3]

Display advertising is where websites allow moving images or a video advertisement of a certain company's product to be published alongside their own webpage.[3]

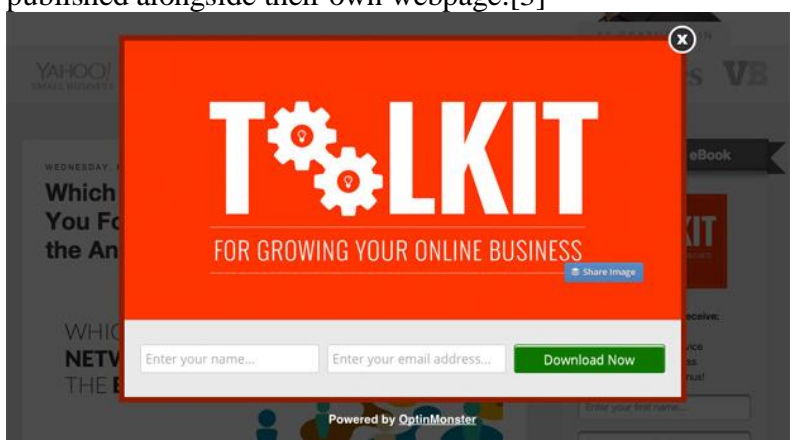

Fig. 3: Email Marketing [4]

Email marketing is a form of marketing where consumers are made aware by viewing the best deals, new products, discounts via electronic mails. [4]

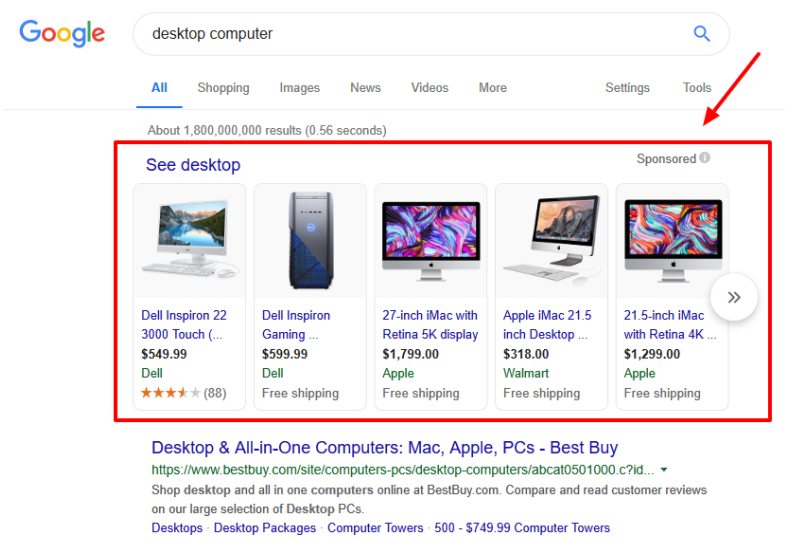

Fig. 4: Search Engine Marketing [5]

Search Engine Marketing is where a special term keyword is used to submit a product or service information on the internet by the advertising firm. Thus, the advertising firm only pays for those who clicked the link for visiting their website. That happens only when a consumer searches for a keyword on the internet and multiple links are available to choose from.[6] 


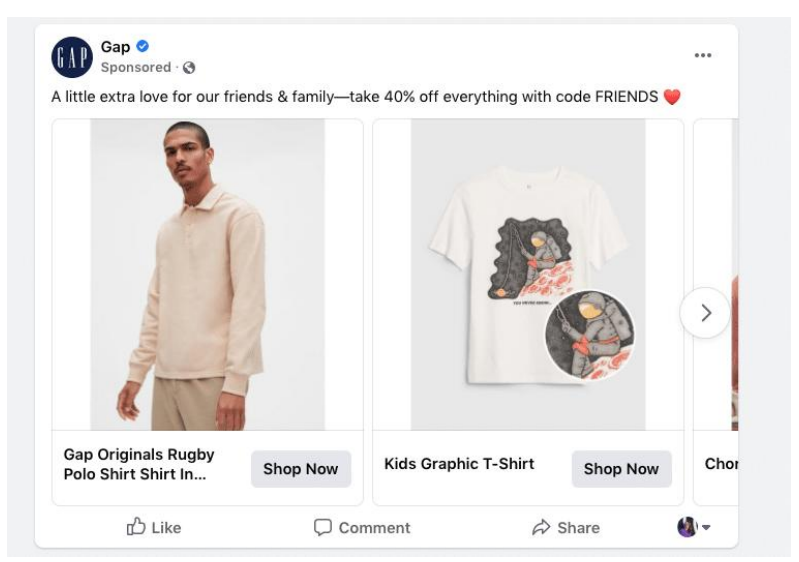

Fig. 5:Social media Marketing [7]

Social media is a type of marketing where advertisements are placed on a social platform by advertising firms. Due to the presence of a huge consumer base available on such social platforms, selling a product can be an easy and is a costreductable approach. Thus, as discussed above some prominent digital marketing platforms, each of them has a specific revenue generator in common and that is the pay-perclick business model (PPC). This model will be discussed in the coming paragraph. Cost-per-click (CPC) is a form of paid advertising on search engines and other displayable websites. It forms an integral part of the search engine revenue model and it functions on a "keyword" bidding system that depends on consumers/users who click on the advertisement related to their product of choice.[6] This type of business model has been popular lately. Most of the tech giants such as Amazon, Google, Facebook, YouTube, etc., use a pay-per-click model for revenue generation. Almost all of their revenue is generated by this model. Research has been conducted over the past few years about such models, in today's digital and economical market such models are considered and given utmost importance for their high amount of usage in almost each and every digital marketing and advertising company. The aim of this paper is to thus present a systematic review of articles currently available on PPC models. The following paragraph discusses PPC models in brief.

\subsection{Types of PPC models}

Pay-per-click can be categorised in two significant models i.e., bid-based and flat-rate PPC models. Consideration must be made by the advertiser regarding the importance of clicks from a legitimate source. This importance of clicks holds a certain value that the advertiser is looking for. The revenue gained by the advertiser totally depends upon such forms of advertising. Other forms of advertising can be implemented too but with PPC models lots of other factors come into play such as target's interest, intent, location, and therefore the day and time that they are browsing.[8]

\subsubsection{Flat rate $P P C$}

Whenever an advertiser and a website publisher of arespective search engine come to an agreement that a particular price would be paid to the advertiser whenever a user clicks on the $\mathrm{ad}$ on the search engines website. This is called the flat rate ppc model. When websites are published for the sake of publishing such models come into play. Where the intention is only to trap the user into clicking the advertisement set up by the search engine publisher. The price is decided and the amount is paid to the advertiser only when the publisher looks for a certain keyword or queries having a group of traffic on the internet.

\subsubsection{Bid based PPC}

The most common and simple way of placing your advertisement on search engines is by using the bid-based model. Huge tech leading companies such as Google, Bing, Firefox have individual publishers who allow advertisers to name and pay their bid for a certain price.

A search has been conducted by some research regarding consumer queries or keywords and when clicked on the advertiser's advertisement, then there is a great potential seen in such regions with huge traffic and the likelihood that they will turn into customers is higher.

In everyday case scenario bid based ppc models are viewed as the best as anyone can place their ads at any time and also it is easy for the publisher to track down keywords or queries, find the best place for the advertiser to place their advertisements etc. The cons of having a PPC model is that it needs a lot of maintenance and man force to look after it.[9]

\subsection{Role of SERP in brief}

Whenever a user searches something online especially on browsers such as Google, Firefox, Safari etc., a Search Engine Results Page is generated. The local search engine generates a SERP whenever the user searches for a query or to be specific a keyword.

The SERP for every search engine is unique and different even though it has the same search queries or keywords. The difference is caused to due to the fact that the online search engines optimise and customise their webpages to a great extent with a wide variety of search terms that are beyond the expectations of the user, this is all done to enhance their experience and guarantees that the user gets what it wants. This enhancement is done considering various factors such as user's browsing history, keyword hunt, browsing settings and much more. Subtle differences in the features can be seen in two or more SERP's resulting the same page. Thus, two or more SERP's can be identical in nature.

The older versions of search engines weren't as reliable than todays. Tech giants such as Google, Firefox, Safari and many other search engines are taking great initiatives in order to provide their best service to the user. The appearance and features are altered and evolved over the time and the effect of this experimentation can be seen in today's search engines. All this experimentation of search engines keeping up with users' relation with the engine led to the evolution where all the queries of a user can be solved. [10]

\section{SYSTEM ARCHITECTURE}

The architecture of the Pay Per Click models will be discussed in this section.

The pay-per-click model is primarily on keywords. For example, in a search engine, online ads (also known as sponsored links) only arise when anyone searches a keyword associated with the products or service being advertised.[10] Hence, companies that rely on pay-per-click advertising model research and examine the keyword most appropriate to their products or services. Investing in related keywords can result in a bigger number of clicks and ultimately, it creates higher profits.[10]

The PPC model is considered helpful for advertisers and publishers respectively. For advertisers, the model can be advantageous because it generates an opportunity to advertise products or services for a definite audience who is actively searching for related content. In addition, the well-designed 
PPC advertising campaign enables the advertiser to save a substantial amount of money as the amount of each visit or click from a potential customer exceeds the cost of the click paid to a publisher.[10] For publishers, the pay-per-click model creates primary revenue streams. Like Google and Facebook, which provide free services to their customers which are free web searches and social networking. Online companies can monetise their free products by online advertising, specifically the Pay-Per-Click model.[10]

\subsection{PPC System}

Companies like Google, Facebook develop a ppc (pay per click) model for the companies who required specific types of customers like youngsters, adults sometimes married or single etc. in such types of a case a System architect of PPC model take the data and understand the behaviour of a user very efficiently and after that those data are stored by companies like Google and Facebook and when any company or any businesses wants to take the ads for a particular kind of customer having particular age, choices, interest, gender will show the ads in front of them. Businesses have to pay them only when the customer clicks on that ad. This System (PPC) is the high-tech system we ever had. It is the most costefficient and most reliable compare to the traditional advertising methods which is not such a refined system.

\subsection{PPC model}

The pay-per-click model means an internet marketing system where you have to pay the fee for every click. It is useful when you are getting organic traffic to websites or your platform. Various search engines, especially Google, give pay-per-click advertising choices. Google Ads uses a system where you bid for ad placement. Whenever someone explores something regarding keywords associating with your product or service, your ad can look in the sponsored links at the top or bottom of the Search Engine Results Page.

\subsection{Advertising in PPC}

PPC is an affordable advertising choice for every type of business. It manages with a budget and is scalable if you're making good returns on your investment. it has multiple advantages: -

i. You get free brand publicity.

ii. You have only to pay when your ad gets click.

iii. Your ad appears when someone is searching related keyword service or product, i.e., there is intent to purchase.

\subsection{While setting up the PPC campaign}

It's deserving investing time and effort in setting up your campaign properly from the start. For it, you have to do the following

i. Studying famous keywords.

ii. Add keywords in ad groups.

iii. Set up PPC landing pages at your website.

\subsection{To get your ad select}

We can learn this from the way Google Ads selects ads for their SERPs. When a user starts a search query, Google searches the supply of advertisers which are targeting such query and chooses a set of champions to look at the top of the SERP. Champions are taken according to the connection of their keywords, the nature of their ad campaign and landing page, and the size of their bid.

\subsection{For a quality Ad campaign}

Google allows an Ad Rank to all advertiser to arrange quality campaigns. It's a range based upon your cost-per-click (CPC)
Bid and Quality Score. The CPC bid is the largest amount you are going to pay for those ads which were clicked by the user.

\subsection{After campaign}

As with all types of advertising, the PPC model also needs to be observed to assure you're receiving the most beneficial returns. Google Ads, in special, encourages you to enhance your campaigns across time by interpreting what is and is not operating and offering suggestions for growth. They additionally do frequent modifications on how their algorithm operates also it is necessary to remain on top of those adjustments. Ultimately, individual of the best aspects of PPC advertising is that it is $100 \%$ measurable. You can follow traffic, leads, phone calls, website pages visited - anything that is meaningful to your business. You always stay updated with what exactly happening and how much you improved in the PPC model. [11]

\section{FUTURE SCOPE}

The Future Scope of PPC in India and around the world is Huge. PPC is the Best Option for a Career. Some Features and Specification in PPC and digital marketing is used -ad setup optimisation, visitor tracking, Geo-Targeting, city Targeting, Website analysis, landing page optimisation, budget monitoring, etc. PPC is the Strong Technique in the world Best Marketing To being the best Businessmen. The global Pay-per-click (PPC) Advertising market is valued at a million US\$ in 2019 and can earn a million US\$ by the end of 2025, developing at a CAGR of during 2020-2025.[12] The objectives of the study would be to define, segment, and also job how big the pay per click (PPC) Advertising market based on company, product type, program, and key regions. This research suggests that the international Pay-per-click (PPC) Advertising market by players/brands, region, type, and application. This report also examines the global market status, rivalry scene, market share, growth rate, prospective trends, market drivers, changes and challenges, sales channels, distributors, clients, research findings and judgment, appendix \& statistics source, and Porter's Five Forces Analysis.[12] In terms of the marketing industry, most offline publications and offline marketing are very limiting. Not only Advertisers can't be sure about how many people see their ads, getting accurate data about Conversation Rates is almost impossible too.[13] Online Ads, on the other hand, offer a lot of control and they have been around here enough to let businesses be comfortable spending money on them. Considering these facts, a career in PPC with only be more valuable in the future.[13]

\section{CONCLUSION}

The purpose of this paper is to offer basic information on Payper-click Model and its importance. CPC may be a common pricing model for Internet advertising during which costs are charged per click, and this model is particularly common in Google AdWords. Here, the value of every click is often calculated via a bid process during which the bidder's status is evaluated consistent with a variety of various criteria. Advertisers can bid to put advertisements either in Google search results or on Google's Display Network.

AdWords is taken into account Google's main source of income and therefore the CPC process is employed by thousands of Internet platforms to auction their most desirable advertising space. 


\section{REFERENCES}

[1] https://nichehacks.com/affiliate-websites/22-exampleslucrative-affiliate-websites.

[2] Adam

Enfroy.(Blogger).https//www.bigcommerce.com/blog/aff iliate-marketing/\#what-is-affiliate-marketing. Accessed

[3] https://mailchimp.com/marketing-glossary/emailmarketing/.

[4] http://dx.doi.org/10.1287/mnsc.1090.1054.

[5] source-https://blog.alexa.com/what-is-sem/ ANINDYA GHOSE, SHA YANG

[6] Kritzinger, W.T. \& Weideman, M., 2017, 'Parallel search engine optimisation and pay-per-click campaigns: A comparison of cost per acquisition', South African Journal of Information Management 19(1), a820. BY JENNIFER YESBECK
[7] WOUTER T. KRITZINGER, MELIUS WEIDEMAN. https://www.facebook.com/.

[8] Yahoo! Search Marketing (May 18, 2010). "Sponsored Search". Website Traffic Yahoo! Search Marketing (formerly Overture). Archived from the original on February 20, 2010. Retrieved May 18, 2010.

[9] http://www.ryanpauladams.com/blog/ppc methods-flatrate-vs-bid-based

[10] https://www.wordstream.com/serp

[11] https://corporatefinanceinstitute.com/

[12] IRIL. https://mrd.co.nz/.

[13] Redial India Solutions Pvt Ltd, B-02, H-140, BSI Business Park, Sec-63, Noida, Uttar Pradesh-201301 BY CHARLES DICKIE.

[14] MADHURI THAKUR.https://www.educba.com/what-isppc/. 